\title{
MEDULLARY BREAST CARCINOMA
}

\author{
S.S. Malyuchik*, R.G. Kiyamova \\ Institute of Molecular Biology and Genetics NAS of Ukraine, Kyiv, Ukraine
}

\begin{abstract}
More then half a million cases each year makes breast cancer the most common malignancy in female. Medullary breast carcinoma (MBC) is a type of invasive ductal breast carcinoma that usually has favorable prognosis and is characterized by the high graded structure, high mitotic rate and heavy lymphoid infiltration. The last feature makes MBC an attractive subject for detailed studies in respect to development of novel immunological approaches for cancer treatment. In this review we have summarized the data on MBC morphology, antigenic repertoire and molecular biology features. The aim of this review was to illuminate the unique biological features and to outline theoretical basis for further investigations of $\mathrm{MBC}$.
\end{abstract}

Key Words: medullary breast carcinoma, lymphoid infiltration, immunoglobulin, antigen.

Around 430000 new cases of breast caner (BC) occur each year in Europe and an estimated of 180510 in USA [1, 2]. Breast cancer is the most commonly diagnosed cancer after non-melanoma skin cancer, and it is the second most common cause of cancer mortality after lung cancer. The lifetime prevalence of breast cancer is about $13 \%$ in women, according to the National Cancer Institute data, and it is extremely rare but highly lethal in men [3]. This statistics is approximately common for all industrialized countries. Hereditary breast cancer is associated with a poorer survival than sporadic counterpart, which may have consequences for treatment [4]. Breast carcinomas are routinely graded according to Scarff - Bloom Richardson modified by Elston and Ellis [5], based on the assessment of tubule formation, nuclear pleomorphism and mitotic counts.

There are several frequent histological types of breast carcinomas: ductal carcinoma in situ, lobular carcinoma in situ, in one hand, and rarely, medullary carcinoma, mucinous carcinoma and tubular carcinoma. Ductal carcinoma in situ (DCIS) is a noninvasive neoplasm originating in the duct, which in some cases can become invasive. Thanks to the increased accessibility of screening mammography technique, DCIS is diagnosed more frequently and accounts for up to $30 \%$ of all malignant breast lesions [3]. In contrast, lobular carcinoma in situ is defined as a proliferation of

Received: January 11, 2008.

${ }^{\star}$ Correspondence: E-mail: malyuchik@ukr.net

Abbreviations used: ACTA2 - actin alpha 2; ACTG2 - actin gamma 2; BC - breast cancer; CCND1 - cyklin D1; CCNE - cyklin E; CEA - carcinoembrionic antigen; Chk2 - checkpoint homolog (S. pombe); CK - cytokeratin; DCIS - Ductal carcinoma in situ; EGFR - epidermal growth factor receptor; EP - extramedullary plasmacytoma; ER - estrogen receptor; ERBB2 - erytroblastic leukemaia viral oncogene homolog 2; HLA-DR - human leukocyte antigen; HMB45 - human melanoma black; GD3 - ganglioside D3; GEF - guanine nucleotide exchange factor; ICAM-1 - adhesion molecule-1; IGFBP - insulin growth factor binding protein; MAC macrophage; MALT - marginal zone B-cell lymphoma; MBC - medullary breast carcinoma; MYC - cMyc; MYL9 - myosin light chain; $\mathrm{NHL}$ - extranodal non-Hodgkin's lymphoma; PBL - primary breast lymphoma; SEREX - serological identification of recombinantly expressed clones; SFRP 1 - secreted Frizzled-related protein 1; TAM - tumor associated macrophages TPM2-beta - tropomyosin. generally small and often loosely cohesive cells originating in the terminal duct-lobular unit, with or without pagetoid involvement of terminal ducts [6].

To a large extent histology determines prognosis, regarding mucinous, medullary and tubular carcinomas as more favorable types. Medullary breast carcinoma (MBC) is characterized by the high graded structure and heavy lymphocytic infiltration, and usually have favorable prognosis. The aim of this review was to illuminate unique biological features and outline theoretical basis to further investigations of medullary breast carcinoma.

\section{LYMPHOCYTIC INFILTRATION IS A UNIQUE FEATURE OF MBC}

Medullary breast carcinoma is well circumscribed and soft in consistency with a homogeneous grey and moist cut surface, although haemorrhage and necrosis were present in some cases. Microscopically, tumors consisted of large tumor cells, showed marked mitotic activity but no striking nuclear pleomorphism [7]. The characteristic feature of MBC is a dense lymphocytic infiltration of the tumor stroma. It is a morphologically and biologically distinct subtype of invasive carcinoma characterized by the presence of solid sheets of large and pleomorphic cells with indistinct cell borders that lead to a syncytial appearance [8], constituting approximately 3-6\% of all invasive breast cancers [9]. At mammograms, MBC appeared as round or oval non-calcified masses with varying degrees of marginal lobulation [10]. Medullary carcinoma has a second type termed atypical. Atypical medullary carcinoma is diagnosed either when more than $25 \%$ of the tumor is not of the classical medullary type, or when the lymphoid infiltration is moderate, or when circumscription is incomplete [11]. Despite the cytological anaplastic features and high mitotic rate, the prognosis for MBC is surprisingly better than for other types of infiltrating ductal carcinomas, with $84 \% 10$-year survival rate, which is significantly higher than for patients with nonMBC (63\%) [12, 13]. The positive correlation between the intensity of lymphoid infiltration and patient's survival suggests that the immune system may be involved in restraining the spread of this type of breast cancer. In several studies was demonstrated that the 
lymphoid infiltration consists of T, B, and plasma cells, with predominance of cytotoxic $C D 8^{+} T$ cells as well as large numbers of $C D 4^{+} \mathrm{T}, \mathrm{B}$, and plasma cells [8]. In other investigation lymphocytic mononuclear tumor inflammatory cells in 16 cases of medullary carcinoma were mostly $\mathrm{CD} 45 \mathrm{RO}^{+} / \mathrm{CD}^{+} \mathrm{T}$ cells while natural killer cells $\left(\mathrm{CD} 57^{+}\right)$and histocytes $\left(\mathrm{MAC} 387^{+}\right.$) were virtually absent [14].

The absence of neutrophils indicates that the tumor-infiltrating leukocytes in MBC accumulate in response to specific stimuli and not to nonspecific inflammatory response caused by tumor necrosis or bacterial agents [13]. Several hypotheses were proposed to explain the biological basis for the favorable prognosis of patients with MBC, including enhanced tumor cell apoptosis [15, 16], elevated levels of metastasis-inhibiting factors [15], increased levels of the adhesion molecule-1 (ICAM-1) expression [17].

Interestingly, that some other cancers also possess prominent lymphoplasmacytic infiltrates associated with a favorable prognosis, suggesting that effective anti-cancer responses may develop spontaneously. However, a large body of evidence suggests that in case of non-MBC breast carcinomas the high level of tumor associated macrophages correlates with poor prognosis [18]. The tumor-promoting activities of tumor associated macrophages (TAM) may be the result of their ability to express numerous tumor-promoting factors, such as growth factors, angiogenic mediators, extracellular matrix degrading enzymes and inflammatory cytokines [19-21]. The inflammatory cytokines promote leukocyte infiltration to sites of inflammation and their expansion is inducible, primarily, by proinflammatory cytokines. It was also suggested that TAM might contribute to tumor progression by the release of reactive oxygen intermediates $[19,20]$. These products may induce mutagenic changes that could result in increased DNA damage and generation of diversity within the tumor $[19,21]$. Therefore, tumor infiltrating $B$ lymphocyte could promote the major tumor suppressive effect in MBC, but in case of other breast carcinomas the efficacy of infiltration is questionable.

The risk factors, such as lymph node status, tumor size, steroid receptor status, and menopausal status, which are known to be of major prognostic importance for all other types of breast cancer, have minimal prognostic value in case of $M B C$, indicating that $M B C$ is a subtype with unique biological features.

It is important that lymphoplasmacytic infiltrates of the breast can be associated not only with MBC, but also appear as a consequence of blood cell diseases, such as extranodal lymphoma or/and extramedullary plasmacytoma (EP). EP is a malignant tumor composed entirely of plasma cells in the absence of bone marrow infiltration. Occurring in soft tissue, EP, frequently appears in upper respiratory tract, oral cavity and rare in the breast [22]. Extranodal non-Hodgkin's lymphoma $(\mathrm{NHL})$ localizes in the breast appears as a primary breast lymphoma [23]. Primary breast lymphoma $(\mathrm{PBL})$ is a rare presentation of extranodal lymphoma.
The most common histology for PBL is the diffuse large B-cell type [24-26] and less frequent is extranodal marginal zone B-cell lymphoma (MALT) [25]. Some authors have speculated that extramedullary plasmacytoma may represent a form of extranodal marginal zone B-cell lymphoma (MALT-type lymphoma) with extreme plasmacytic differentiation [27].

In the case of localization in breast these diseases may be readily mistaken for medullary breast carcinoma not only clinically, but also on cytological examination. Since microscopic and histological analysis often shows similar morphology of different types of breast tumors, investigation of gene expression profile could help to discriminate between these tumors. Immunohistochemically, the extramedullary plasmacytomas cells are focally positive for vimentin, diffusely strongly positive for immunoglobulin IgA and kappa light chains, and negative for IgG, IgM, lambda light chains, leukocyte common antigen, CD20, cytokeratin, S100, HMB45, and smooth muscle antigen [22]. In contrast, $\mathrm{MBC}$ is dominantly IgG positive [13], and expresses all the glandular type cytokeratins, including CK19 [28]. Immunohistochemical analysis of primary breast diffuse large B-cell lymphoma showed positive staining for melanoma associated antigen (mutated) 1 (MUM1), Bcl-2 (in one-half cases) and negative for CD10 [29]. Thus, in spite of similar morphology of MBC and PBL or EP, these types of tumors could be distinguished based on analysis of gene expression.

\section{ANTIGENIC REPERTOIRE OF MBC}

Continuing progress in the development of antigen specific breast cancer vaccines depends on the identification of appropriate target antigens, the establishment of effective immunization strategies, and the ability to circumvent immune escape mechanisms. Methods, such as T cell epitope cloning and serological expression cloning (SEREX), have led to the identification of a number of antigens expressed in breast cancer [30]. At first, target antigens must be presented as processed peptides, bound to MHC class I and class II molecules. Recognition of these MHC-peptide complexes on the surface of antigen presenting cells by antigen-specific $\mathrm{T}$ lymphocytes, together with additional co-stimulation, leads to the proliferation of antigen-specific $\mathrm{CD} 8^{+}$and $\mathrm{CD} 4^{+} \mathrm{T}$ cells that have lytic and immunostimulatory functions [30]. In some solid tumors immunocompetent B cells are known to contribute to spontaneous tumor regression [31]. Both naturally occurring and vaccine-induced antibody responses to breast cancer antigens could be associated in some cases with improved survival [32]. One of the first target molecules to be examined in the context of a breast cancer vaccine is carcinoembrionic antigen (CEA), a differentiation antigen of the gut, expressed exclusively in normal colonic epithelium and approximately in $50 \%$ of breast cancers [33]. With regard to clinical trials, Morse et al. [34] have observed objective responses in patients with metastatic disease, including breast cancer, following 
immunization with dendritic cells pulsed with human leukocyte antigen (HLA)-A2 restricted CEA peptide. Recently, a new differentiation antigen of the breast, NY-BR-1, was identified by SEREX analysis, and it was found to be expressed exclusively in normal testis and breast, as well as in $80 \%$ of breast cancers [35]. Their significance in relation to breast cancer vaccines is under investigation [30]. Additionally, MBC and atypical MBC differ in expression profile of some antigens, such as human leukocyte antigen (HLA)-DR and $\beta 2$ microglobulin [36].

Since the high density of B lymphocytes infiltration in MBC may reflect an ongoing immune response against transformed cells, it is of great interest to identify the B-cells targets as important implications for detection and treatment, not only for the MBC, but all other types of breast cancer. The novel techniques for antigen searching in MBC are predominantly based on the analysis of libraries containing variable regions of immunoglobulin genes of tumor infiltrating B cells. In one of this investigation Ig-rearranged $\mathrm{V}$ region $\mathrm{Vh}$-Jh, $\mathrm{VK}_{\mathrm{K}}-\mathrm{JK}_{\mathrm{K}}$, and $\mathrm{V} \lambda-\mathrm{J} \lambda$ genes, amplified by RT-PCR of the infiltrating $B$ cells, were cloned, sequenced, and subjected to a comparative DNA analysis. A combinatorial single-chain Fv $\mathrm{K}$ (scFvK) minilibrary from selected $\mathrm{V}_{\mathrm{H}}$ and $V_{K}$ region genes was generated and tested thereafter for the breast tumor cell-binding capacity. The specific binding was confirmed by FACS analysis with primary breast carcinoma cells and ELISA. Thin layer chromatography and dot-blot experiments showed this target antigen to be a ganglioside D3 (GD3) [37]. Gangliosides have been extensively investigated for their structural and functional properties [38], as well as their role in tumor cell transformation and potential capacity as suitable tumor targets for diagnostics or therapeutics. In addition to the well-defined GD2 overexpression in neuroblastomas and melanomas $[39,40]$, GD3 may be the useful marker MBC.

In other research, in order to determine the role of the antibody response produced by the local infiltrating cells B lymphoplasmacytic cell infiltrates were analyzed in $\mathrm{MBC}$ [13]. IgG antibody phage display libraries were generated from MBC-infiltrating lymphoplasmacytic cells of two patients, and MBC-reactive monoclonal antibodies were retrieved by selection on fresh-frozen MBC tissue sections. Mass spectrometry analysis revealed that the antigen targeted by the dominant clones in the oligoclonal B Iymphoplasmacytic response in both patients was not a cancer-specific antigen but the cytoskeletal actin protein.

MBC exhibits an increased rate of apoptosis, and apoptotic MBC cells were shown to expose actin on the cell surface, permitting its recognition by the humoral immune system. Further, actin fragments, similar to those observed after cleavage with the apoptotic protease granzyme B, were observed in MBC tissue [13].

In general, these results demonstrate the use of clonal analysis and antibody phage display technology in dissection of a local immune response and identification of tumor-associated antigens as targets for cancer immunotherapy. Further elucidation of the immune response in $\mathrm{MBC}$ and the biological features intrinsic to these cancer cells should give clues to the favorable prognosis of MBC.

\section{MOLECULAR BIOLOGY OF MBC}

The fact that the tumor cells harbor a multitude of genetic defects suggests that survival or response to cancer therapy is not associated with a single genetic defect but may result from a combination of various defects. The molecular mechanism behind the frequently detected instability of the genome of breast cancer cells is poorly understood, but some studies have shown the association with mutations in the $p 53$, $B R C A 1$ or BRCA2 genes [41]. BRCA1 and BRCA2 mutations were found in over $90 \%$ of all hereditary breast cancer cases but in contrast to BRCA1, a BRCA2 mutation also confers an increased risk for breast cancer in male [42]. p53 and BRCA1/BRCA2 are tumor-suppressor genes involved in apoptosis [43], transcriptional regulation [44], DNA double-strand repair [45], cell-cycle arrest [46], etc. The new roles for BRCA1 in heterochromatin formation in chromosome Xand ubiquitination have been identified recently [47]. BRCA1 associated tumors are usually estrogen receptor (ER) negative (between 63 and 90\%) [48, 49], while the majority of BRCA2 associated cancers are ER-positive [50].

In addition, it was suggested that ER expression in BRCA1 associated tumors is related to the age of patients $[48,50]$. The most common tumor suppressor gene mutations detected in about $1 / 4$ of breast tumors are in the $p 53$ gene. Mutations in $p 53$ gene are found in $20-40 \%$ of invasive breast cancers and its overexpression detected in $37-77 \%$ of BRCA1 associated tumors [51]. The direct functional link between p53 and $B R C A 1$ was initially suggested by the observation that loss of $p 53$ can partially rescue embryonic lethality in BRCA1 knockout mice [52]. Breast carcinomas with p53 mutations are consistently associated with negative assays for ER and progesterone receptor (PR) [53], and variably associated with amplification of some oncogenes, such as HER-2/neu, c-myc and ras. Overexpression of HER2 protein is found extremely rare in breast carcinomas with BRCA1 mutations. However, HER2/neu overexpression is found in $25-30 \%$ cases of breast cancers [52].

The alterations in these genes are more common for MBC. The present data indicate that p53 alteration is an important factor in typical MBC but probably combines with other specific genetic defects that could explain the paradoxically increased sensitivity of $\mathrm{MBC}$ to treatment. In the typical MBC the frequency of p53 mutations ranges from 50 to $100 \%$ [51]. The percentage of HER-2/neu expression in MBC ranged from less than $10 \%$ to $33 \%$, depending on the sample size of MC cases, detection method used, and the criteria for defining MBC [54].

It was shown that MBC also have been associated with early-onset hereditary breast carcinomas 
due to the BRCA1 gene mutations [47]. Medullary carcinomas, which harbor p53 and Chk2 mutations (human homolog of Rad53), have the high frequency of methylation dependent transcriptional silencing of BRCA1 [55].

The MBC shows enhanced tumor cells apoptosis, elevated levels of metastasis-inhibiting factors, elevated levels of adhesion molecule ICAM- 1 and the effective host immune response [56]. The genes most frequently involved in breast carcinogenesis (MYC, CCND1, EGFR and CCNE) very rarely amplified in MBC [57]. Recently 265 genes that involved in the architecture and remodeling of cytoskeleton were identified as underexpressed in basal MBCs by microarray assay. Among them there are actins (ACTG2, ACTA2), a-actinin (ACTN1), myosin light chain (MYL9), B-tropomyosin (TPM2), and several regulators or associated proteins [9].

The recent investigations have identified a number of genes, including several members of the GAGE and insulin growth factor binding protein (IGFBP) gene families, Vav1 (guanine nucleotide exchange factor (GEF)), monoglyceride lipase and $\mathrm{NADP}^{+}$dependent malic enzyme, which exhibited altered expression in MBC versus ductal breast cancer [9]. By immunohistochemical analysis it was established that the expression of monoglyceride lipase was restricted to ductal breast cancer, and was found in $77 \%$ of these tumors, while Vav1 was restricted to $\mathrm{MBC}$ and was present in $60 \%$ of tumors [9]. The MBC differs from ductal carcinoma by high expression level of human lymphocytic antigen HLA-DR, one of the major histocompatibility complex class (MHC II) antigens, which normally present in all nucleated cells [30]. Recently, it has been reported that the loss of secreted Frizzledrelated protein 1 (SFRP 1) gene, a putative tumor suppressor protein involved in the WNT [58] pathway, was observed in most invasive ductal carcinomas but not shown in MBC [53]. The absence of apoptosis inhibitor protein $\mathrm{Bcl}-2$ expression in $\mathrm{MBC}$ has been described also [59]

The detection of the alterations in these genes would allow to understand the nature of MBC more clearly, and to create new gene therapy strategies in the nearest future.

\section{FURTHER PERSPECTIVES OF BREAST CANCER TREATMENT}

Systemic adjuvant chemo-, endocrine -and/or radiotherapy are the first line treatment in breast cancer after surgery of the primary tumor, directed to eradicate disseminated tumor cells as a potential cause of metastatic growth. Unfortunately, the heterogeneity of solid tumors including different cell cycle phases and resistance mechanisms create a problem for all kinds of therapy, and limit the chance of complete elimination of all residual tumor cells.

The implementation of screening programs for the early detection of breast cancer and the development of the chemotherapy, radiotherapy, and anti-estrogen therapies has improved the survival of the breast cancer patients. The development of target selective therapy is the next step in breast cancer treatment. So, the identification of proteins and/or antigens, which expression is elevated in breast cancer tissues compared with normal breast tissue, is an important step in the development of breast cancer therapies [60]. The tumor-associated antigens are the keys for the development of anti-cancer vaccines and monoclonal antibodies, which could make cancer therapy more harmless and efficient. Monoclonal antibody Herceptin, generated against ERBB2 receptor (her2/neu), successfully used in breast cancer treatment [61]. Dense lymphocytic infiltration of MBC enables assumption of existence of one or few highly expressed autoantigens, which could make basis for further investigations in immunotherapy of breast carcinomas. Further investigation of ganglioside D3 and actin overexpression in MBC could extend the antigen repertoire, and allow developing active or passive immunotherapy for MBC treatment. All aforesaid treatment strategies have their pluses and minuses, but restrictions of classical cancer treatment will drive researchers to search for novel strategies for breast cancer treatment.

\section{CONCLUSIONS}

A relatively favorable prognosis for MBC correlates with heavy lymphocytic infiltration of this tumor. Absence of IgA antibody that predominates in normal breast tissue, and generally presence of $\lg G$ is a sign of antigen-specific immune response in MBC. It has been hypothesized that infiltrating plasma cells react with an antigen and directly or indirectly involved in control of tumor progression. Several investigations of MBC antigenic repertoire found a number of highly expressed tumor specific antigens such as $\beta$-actin, ganglioside D3, HLA-DR and $\beta 2$-microglobulin. These antigens could be considered as targets for cancer immunotherapy as well as for generation therapeutic monoclonal antibodies.

Further search for antigens, present in MBC, could bring the light on nature of favorable prognosis not only in MBC, but in the other types of breast carcinomas as well. The understanding of the role of the infiltrating elements in MBC would help to create efficient therapeutic strategies for breast cancer treatment.

\section{REFERENCES}

1. Ferlay J, Autier P, Boniol M, et al. Estimates of cancer incidence and mortality in Europe in 2006. Ann Oncol 2007; 18: 581-92.

2. Lester J. Breast cancer in 2007: incidence, risk assessment, and risk reduction strategies. Clin J Oncol Nurs 2007; 11: 619-22.

3. Li CI, Daling JR, Malone KE. Age-specific incidence rates of in situ breast carcinomas by histologic type, 1980 to 2001. Cancer Epidemiol Biomarkers Prev 2005; 14: 1008-11.

4. van der Groep P, Bouter A, van der Zanden R, et al. Distinction between hereditary and sporadic breast cancer on the basis of clinicopathological data. J Clin Pathol 2006; 59: 611-7. 
5. Elston CW, Ellis IO. Pathological prognostic factors in breast cancer. The value of histological grade in breast cancer: experience from a large study with long-term follow-up. Histopathology 1991; 19: 403-10.

6. Tavassoli FA, Devillee P. World Health Organisation Classification of tumours: pathology and genetics of tumours of the breast and female genital organs. Lyon: IARC Press; 2003.

7. Shousha S. Medullary carcinoma of the breast and BRCA1 mutation. Histopathology 2000; 37: 182-5.

8. Ridolfi RL, Rosen PP, Port A, et al. Medullary carcinoma of the breast: a clinicopathologic study with 10 year follow-up. Cancer 1977; 40: 1365-85.

9. Gjerstorff MF, Benoit VM, Laenkholm AV, et al. Identification of genes with altered expression in medullary breast cancer vs ductal breast cancer and normal breast epithelia. Int J Oncol 2006; 8: 1327-35.

10. Mayer JE, Karen EA, Lindfors K, et al. Medullary carcinoma of the breast: Mammographic US appearance. Radiology 1989; 170: 79-89.

11. Honrado E, Benýtez J, Palacio J. Histopathology of BRCA1- and BRCA2-associated breast cancer. Critical Rev in Oncol/HematoL 2006; 59: 27-39.

12. Pedersen L, Zedeler K, Holck S, et al. Medullary carcinoma of the breast. Prevalence and prognostic importance of classical risk factors in breast cancer. Eur J Cancer 1995; 31: 2289-95.

13. Hansen MH, Nielsen HV, Ditzel HJ. Translocation of an intracellular antigen to the surface of Medullary breast cancer cells early in apoptosis allow for an antigen-driven antibody response elicted by tumor infiltrating B cells. J Immun 2002; 169: 2701-11.

14. Gaffey MJ, Frierson HF Jr, Mills SE, et al. Medullary carcinoma of the breast. Identification of lymphocyte subpopulations and their significance. Mod Pathol 1993; 6: 721-8.

15. Jensen V, Jensen ML, Kiaer H, et al. MIB-1 Expression in breast carcinomas with medullary features. Virchows Arch 1997; 431: 125-30.

16. Yakirevich E, Maroun L, Cohen O, et al. Apoptosis, proliferation, and fas (APO-1, CD95) / Fas ligand expression in medullary carcinoma of the breast. J Pathol 2000; 192: 166-73.

17. Bacus SS, Zelnick CR, Chin DM, et al. Medullary carcinoma is associated with expression of intercellular adhesion molecule-1. Implication to its morphology and its clinical behavior. Am J Pathol 1994; 145: 1337-48.

18. Ben-Baruch A. Host microenvironment in breast cancer development inflammatory cells, cytokines and chemokines in breast cancer progression: Reciprocal tumor-microenvironment interactions. Breast Cancer Res 2003; 5: 31-6.

19. Leek RD, Harris AL. Tumor-associated macrophages in breast cancer. J Mammary Gland Biol Neoplasia 2002; 7: $177-89$.

20. Crowther M, Brown NJ, Bishop ET, Lewis CE. Microenvironmental influence on macrophage regulation of angiogenesis in wounds and malignant tumors. J Leuk Biol 2001; 70: 478-90.

21. Balkwill F, Mantovani A. Inflammation and cancer: back to Virchow? Lancet 2001; 357: 539-45.

22. De Chiara A, Losito S, Terracciano L, et al. Primary plasmacytoma of the breast. Arch Pathol Lab Med 2001; 125: $1078-80$.

23. Serafi AA, Delgado M, Nambo J, et al. Primary breast lymphoma: results of a controlled clinical trial. Oncology 2005; 69: 256-60.

24. Sutcliffe SB, Gospodarowicz MK. Clinical features and management of localized extranodal lymphomas. In Keating A, Armitage J, Burnet A, Newland A (eds): Haema- tological Oncology, Cambridge: Cambridge University Press 1992; 2: 189-223.

25. Bobrow LG, Richards MA, Happerfield LC, et al. Breast lymphomas: A clinicopathologic review. Hum Pathol 1993; 24: 274-8.

26. Jeon HJ, Akagi T, Hoshida Y, et al. Primary non-Hodgkin malignant lymphoma of the breast. An immunohistochemical study of seven patients and literature review of 152 patients with breast lymphoma in Japan. Cancer 1991; 70: 2451-9.

27. Hussong JW, Perkins SL, Schnitzer B, et al. Extramedullary plasmacytoma. A form of marginal zone cell lymphoma? Am J Clin Pathol 1999; 111: 111-6.

28 . Tot $\mathbf{T}$. The cytokeratin profile of medullary carcinoma of the breast. Histopathology 2000; 37: 175-81.

29. Yoshida S, Nakamura N, Sasaki Y, et al. Primary breast diffuse large B-cell lymphoma shows a non-germinal center B-cell phenotype. Modern Pathology 2005; 18: 398-405.

30. Scanlan MJ, Jäger D. Challenges to the development of antigen-specific breast cancer vaccines. Breast Cancer Res 2001; 3: 95-8.

31. Zhang NZB, Demetrikopoulos MK, Kitson RP, et al. Evidence for involvement of B lymphocytes in the surveillance of lung metastasis. Cancer Res 1999; 59: 1080-9.

32. Coronella, JA, Hersh EM. Naturally occurring B-cell responses to breast cancer. Cancer Immunol. Immunother 2003; 52: 715-38.

33. Hodge JW. Carcinoembryonic antigen as a target for cancer vaccines. Cancer Immunol Immunother 1996; 43: 127-34.

34. Morse MA, Deng Y, Coleman D, et al. A Phase I study of active immunotherapy with carcinoembryonic antigen peptide (CAP-1)-pulsed, autologous human cultured dendritic cells in patients with metastatic malignancies expressing carcinoembryonic antigen. Clin Cancer Res 1999; 5: 1331-8.

35. Jager D, Unkelbach M, Frei C, et al. Identification of tumor-restricted antigens NY-BR-1, SCP-1, and a new cancer/ testis-like antigen NW-BR-3 by serological screening of a testicular library with breast cancer serum. Cancer Immun 2002; 2: 5.

36. Feinmesser M, Sulkes A, Morgenstern S, et al. HLA-DR and $\beta 2$ microglobulin expression in medullary and atypical medullary carcinoma of the breast: histopathologically similar but biologically distinct entities. J Clin Pathol 2000; 53: 286-91.

37. Kotlan B, Simsa P, Teillaud JL, et al. Novel ganglioside antigen identified by B cells in human medullary breast carcinomas: The proof of principle concerning the tumorinfiltrating B lymphocytes. J Immunol 2005; 175: 2278-85.

38. McKallip R, Ruixiang L, Ladisch S. Tumor gangliosides inhibit the tumor-specific immune response. Immunol 1999; 163: $3718-26$.

39. Mitchell MS. Cancer vaccines, a critical review-part II. Curr Opin Invest Drugs 2002; 3: 150-8.

40. Moutel S, Birkle S, Laurence V, Michon, et al. Generation and characterization of a mouse single-chain antibody fragment specific for disialoganglioside (GD2). Hybridoma 1997; 16: 335-46.

41. Ingvarsson S. Molecular Genetics of Breast Cancer. Int J Hum Genet 2003; 3: 69-78.

42. Szabo CI, King MC. Population genetics of BRCA1 and BRCA2. Am J Hum Genet 1997; 60: 1013-20.

43. Harkin DP, Bean JM, Miklos D, et al. Induction of GADD45 and JNK/SAPK-dependent apoptosis following inducible expression of BRCA1. Cell 1999; 97: 575-86.

44. Brodie SG, Deng CX. BRCA1-associated tumorigenesis: what have we learned from knockout mice? Trends Genet 2001; 17: 18-22. 
45. MacLachlan TK, Dash BC, Dicker DT, El-Deiry WS. Repression of BRCA1 through a feedback loop involving p53. J Biol Chem 2000; 275: 1869-75.

46. Xu B, Kim S, Kastan MB. Involvement of Brcal in S-phase and $\mathrm{G}(2)$-phase checkpoints after ionizing irradiation. Mol Cell Biol 2001; 21: 3445-50.

47. Lea M, Starita and Jeffrey D, Parvin. The multiple nuclear functions of BRCA1: transcription, ubiquitination and DNA repair. Curr Opin Cell Biol 2003; 15: 345-50.

48. Foulkes WD, Metcalfe K, Sun P, et al. Estrogen receptor status in BRCA1- and BRCA2-related breast cancer: the influence of age, grade, and histological type. Clin Cancer Res 2004; 10: 2029-34.

49. Putti TC, Abd El-Rehim DM, Rakha EA, et al. Estrogen receptor-negative breast carcinomas: a review of morphology and immunophenotypical analysis. Mod Pathol 2005; 18: 3526-50.

50. Eerola H, Heikkila P, Tamminen A, et al. Relationship of patients age to histopathological features of breast tumours in BRCA1 and BRCA2 and mutation-negative breast cancer families. Breast Cancer Res 2005; 7: 465-9.

51. de Cremoux P, Salomon AV, Liva S, et al. p53 mutation as a genetic trait of typical medullary breast carcinoma. $\mathbf{J}$ Natl Cancer Inst 1999; 91: 641-3.

52. Grushko TA, Blackwood MA, Schumm PL, et al. Molecularcytogenetic analysis of HER-2/neu gene in BRCA1associated breast cancers. Cancer Res 2002; 62: 1481-8.

53. Ross LS, Linette GP, Stec L, et al. Breast cancer biomarkers and molecular medicine part 2. Expert Rev Mol Diagn 2004; 4: 169-88.
54. Xu R, Feiner H, Li P, et al. Differential amplification and overexpression of HER-2/neu, p53, MIB1, and estrogen receptor/progesterone receptor among medullary carcinoma, atypical medullary carcinoma, and high-grade invasive ductal carcinoma of breast archives of pathology and laboratory medicine 2003 127; 11: 1458-64.

55. Sullivan A, Yuille M, Repellin C, et al. Concomitant inactivation of $\mathrm{p} 53$ and $\mathrm{Chk} 2$ in breast cancer. Oncogene 2002; 21: 1316-24.

56. Verhoeven ICL, Hillen HFP, Wagstaff J, et al. Agiogenic profile of breast carcinoma determines leukocyte infiltration. Clin Cancer Res 2004; 10: 7171-8.

57. Salomon AV, Gruel N, Lucchesi C, et al. Identification of typical medullary breast carcinoma as a genomic sub-group of basal-like carcinomas, a heterogeneous new molecular entity. Breast Cancer Res 2007; 9: 24.

58. Rijsewijk F, Schuermann M, Wagenaar E, et al. The Drosophila homolog of the mouse mammary oncogene int-1 is identical to the segment polarity gene wingless. Cell 1987; 50: 649-57.

59. Jensen V, Jensen ML, Kiaer H, et al. MIB-1 expression in breast carcinomas with medullary features: an immunohistological study including correlations with p53 and bcl-2. Virchows Arch 1997; 431: 125-30.

60. Adam PJ, Berry J, Loader JA, et al. Arylamine NAcetyltransferase-1 Is Highly Expressed in Breast Cancers and Conveys Enhanced Growth and Resistance to Etoposide in Vitro. Mol Cancer Res 2003; 1: 826-35.

61. Zhou J, Zhong Y. Breast cancer immunotherapy. Cell Mol Immunol 2004; 1: 247-55.

\section{МЕДУЛЛЯРНАЯ КАРЦИНОМА МОЛОЧНОЙ ЖЕЛЕЗЫ}

Рак молочной железы является наиболее распространенным онкологическим заболеванием среди женщин. Медуллярная карцинома молочной железы (МКМЖ) представляет собой вид инвазивного рака протоков молочной железы, который часто имеет благоприятный прогноз, характеризуется высоким уровнем дифференцировки, высоким митотический индексом и выраженной лимфоидной инфильтрацией. Именно это свойство делает МКМЖ привлекательной мишенью для детального изучения при разработке новых иммунотерапевтических подходов к лечению рака. В данном обзоре мы суммировали данные о морфологии, антигенном спектре и особенностях молекулярной биологии МКМЖ. Основная цель обзора - освещение уникальных биологических особенностей и определение теоретической основы для дальнейших исследований МКМЖ. Ключевые слова: медуллярная карцинома молочной железы, лимфоидная инфильтрация, иммуноглобулин, антиген. 